\title{
VELOCITIES OF MAJOR OUTLET GLACIERS OF THE PATAGONIA ICEFIELD OBSERVED BY TERRASAR-X
}

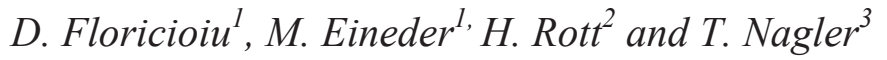 \\ ${ }^{1}$ DLR-IMF, Oberpfaffenhofen, Germany \\ ${ }^{2}$ Institut für Meteorologie und Geophysik, Universität Innsbruck, Austria \\ ${ }^{3}$ ENVEO IT, Innsbruck, Austria \\ E-mail: dana.floricioiu@dlr.de
}

\begin{abstract}
The capabilities of TerraSAR-X data for feature tracking by amplitude correlation over glacier surfaces are investigated. Methodical aspects of the amplitude correlation approach are described. The TerraSAR-X based velocity fields are compared with former InSAR derived velocities and field measurements on three outlet glaciers on the South Patagonia ice field.
\end{abstract}

\section{Index Terms - TerraSAR-X, glacier velocity, Patagonia}

\section{THE STUDY GLACIERS}

The behavior of the Patagonia Icefields, the largest temperate ice masses in the Southern Hemisphere, is of importance for understanding the global climate system.

The main outlet glaciers of the Southern Patagonia ice field (SPI) terminate with calving fronts, so that the calving flux is an important component of the mass balance. The response of calving glaciers to climate forcing is complex, influenced by various factors in addition to the climate signal.

Previously, interferometric ice motion data have been obtained for several glaciers of the SPI from $24 \mathrm{~h}$ repeat pass L-band SIR-C data of SRL-2 in October 1994 [1]. For a few glaciers data from field work are available [2], [3]. ERS tandem data could be applied only on few glaciers because of decorrelation due to adverse meteorological conditions (frequent snowfall, rain, melting) or strong shear deformation on the glacier tongues. A new tool appropriate for such investigations is the TerraSAR-X satellite, launched on 15 June 2007, which carries onboard an X-band SAR $(9.65 \mathrm{GHz})$. Correlation techniques with 11-days repeat-pass amplitude TerraSAR-X images can be applied for ice motion studies also on fast flowing glaciers.

So far our work with TerraSAR-X data has focused at three outlet glaciers of the SPI that are calving into the Lago Argentino (Fig. 1): Upsala glacier covering $902 \mathrm{~km}^{2}$ in area, Moreno glacier $\left(254 \mathrm{~km}^{2}\right)$ and Ameghino (74 $\mathrm{km}^{2}$ ). For Upsala glacier geodetic measurements have been made during some periods in the 1990s at stakes near the front [4].

On the terminus of Moreno glacier ice velocity has been measured in the field for 8 years, 1995 - 2003 [2]. On Ameghino glacier ice motion was measured at stakes near the front in 1999-2000. In addition, interferometric ice motion maps have been derived from L-band SIR-C data of October 1994 for Moreno and Ameghino glaciers [1], [5]. Whereas Moreno Glacier is in a balanced state since many years, the two other glaciers have been receding during the last few years.

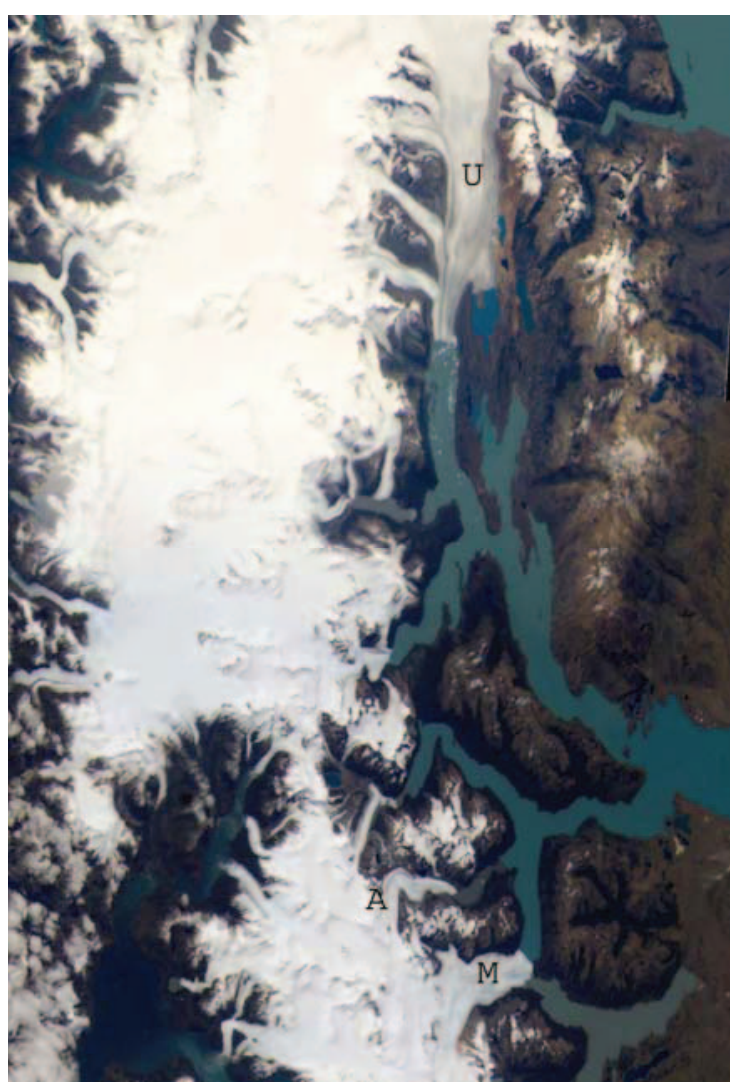

Fig. 1: ISS digital photograph taken in January 2002 showing the study glaciers of the Southern Patagonia Icefield. U - Upsala, M - Moreno, A - Ameghino glaciers. 


\section{TERRASAR-X DATA BASE}

The investigations presented in this paper are based on TerraSAR - X repeat pass data acquired in stripmap mode during four 11-days cycles between end of December 2007 and end of January 2008 (Table 1).

Table 1: TerraSAR-X data acquisitions and characteristics used for ice motion analysis. A- ascending, D descending orbit.

\begin{tabular}{|l|l|l|l|}
\hline $\begin{array}{l}\text { TSX Acquisition } \\
\text { date/time UTC }\end{array}$ & $\begin{array}{l}\text { Relative } \\
\text { orbit }\end{array}$ & Beam & $\begin{array}{l}\text { Incidenc } \\
\text { e angle }\end{array}$ \\
\hline $\begin{array}{l}\text { Moreno/Ameghin } \\
\text { o }\end{array}$ & & & \\
\hline $29.12 .2007 / 23: 53$ & $165 / \mathrm{A}$ & strip_009 & $41 \mathrm{deg}$ \\
9.01 .2008 & & & \\
20.01 .2008 & & & \\
31.01 .2008 & & & \\
\hline Upsala & & & \\
\hline $27.12 .2007 / 09: 53$ & $126 / \mathrm{D}$ & strip_009 & $41 \mathrm{deg}$ \\
7.01 .2008 & & & \\
18.01 .2008 & & & \\
29.01 .2008 & & & \\
\hline
\end{tabular}

The TerraSAR-X data were operationally processed into the Enhanced Ellipsoid Corrected (EEC) Spatially Enhanced (SE) product with a pixel spacing of $1.25 \mathrm{~m}$ in range and azimuth. At 41 deg incidence angle the ground range and azimuth resolution are $3 \mathrm{~m}$ with an effective number of looks of 1.2 .

\section{METHODOLOGY}

Previous maps of ice motion on the investigated glaciers [2] were based mainly on SAR interferometry which delivers the wrapped relative spatial slant range displacement between two pixels. While SAR interferometry can achieve an accuracy smaller than a wavelength down to the millimeter range, the method suffers from a number of disadvantages:

- The arrangement of elementary scatterers in a resolution cell (pixel) must stay unchanged (in the wavelength scale) between the two acquisitions. Otherwise the phase decorrelates. The dynamic processes on glacier surfaces (melting, snowfall) typically lead to decorrelation within a few days, or even within a few hours. For that reason, repeat pass interferometry measurements of glacier velocities were based on the opportunities when short revisit cycles were available: the SIR-C/X-SAR mission in 1994 (1 day repeat), the ERS$1 / 2$ tandem phase 1995 - (1 day repeat) and the ERS-1 ice phase (3 day repeat).

- Interferometric measurements suffer from phase ambiguity problems. Phase unwrapping must be performed to derive relative velocity fields. A tie point is needed to convert the relative velocity fields to absolute measurements. If larger decorrelated regions exist on the surface, then the relationship between different regions of the velocity map may get lost.

- $\quad$ The rather fast velocity of many glaciers leads to significant local shifts between the images. These shifts need to be estimated to sub-resolution scale before an interferogram can be generated at all.

- $\quad$ Only the slant range projection of the true 3D velocity vector is measured. The derivation of the vector requires the knowledge of the ice flow direction.

None of the above problems is present in our approach that takes advantage of the high resolution and the geometric accuracy of TerraSAR-X.

We use an incoherent amplitude correlation approach. Therefore no temporal stability of the speckle pattern is required and the local roughness of ice surface features suffices. Still, stability (=coherence) of the speckle pattern would help to track homogenous snow covered surfaces without amplitude features.

The correlation measurements are unambiguous and absolute with respect to the orbital geometry of the satellite. No tie-points are needed. Overall biases caused by orbital errors $(<0.1 \mathrm{~m})$ and atmospheric path delay variations $(<0.3 \mathrm{~m})$ over one repeat cycle (11 days) should be smaller than $0.4 \mathrm{~m} / 11$ days $=0.036 \mathrm{~m} /$ day.

For assumed maximal glacier velocities of $5 \mathrm{~m} /$ day the displacement between two successive images (11 days) is on the order of 55 meters, i.e. about 50 pixels in our EEC SE product. This displacement is easily caught within our correlation block size on the order of $128 \times 128$ to $256 \times 256$ pixels.

The amplitude correlation method delivers a 2D displacement vector in range and azimuth. Since we perform the correlation on geocoded products (EEC), the displacement vector is derived directly in ground geometry, even if in reality the projections to azimuth and slant range are derived. The EEC product is in fact a product that has been geocoded with the best available DEM [6]. In our example a combination of C-band $(90 \mathrm{~m}$ resolution) and X-band ( $30 \mathrm{~m}$ ) SRTM DEM was used.

The signal processing flow of our current prototype implementation is sketched in Fig. 2. As mentioned before we start with high resolution detected EEC products. Then the region of interest (ROI) is extracted from each image using only the geometric annotation information of the EECs. The resulting pixel shift was always integer valued for all products, presumably because of the common raster of multiple of $1.25 \mathrm{~m}$.

Having in mind a future pyramid implementation of the correlation algorithm, we then perform an averaging of the images starting with $8 \times 8$ and ending at full resolution. A low pass filtered resolution image is then subtracted to enhance the image contrast which stabilized the correlation.

The smoothed images are correlated with a local block size between $128^{2}$ and $256^{2}$ pixels. The individual blocks are incremented by $1 / 4$ blocksize. The displacement vector 
for each block is derived from the maximum in the correlation matrix and the correlation factor is calculated for that position. We achieved stable results even with $4 \times 4$ pixel smoothed images, i.e., with a resolution reduced to 12 meters. Our example images show the results from the $4 \times 4$ smoothed versions which can be computed in a couple of hours on a UNIX workstation.

Finally, a coloured overlay image is computed by adding the colored velocity map on the grey scale radar intensity map. The overlay is weighted with the coherence of the estimate.

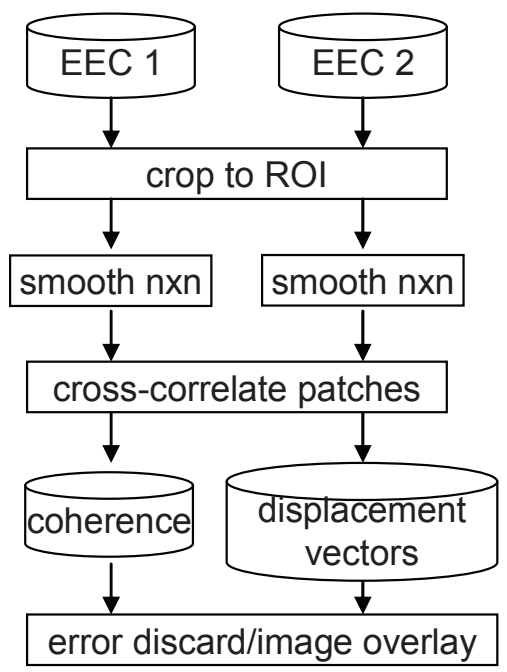

Fig. 2: Processing flow of the SAR amplitude correlation method.

\section{GLACIER VELOCITY FIELDS}

The SAR amplitude correlation technique described above was applied to TerraSAR-X data to map ice motion in the ablation area of the three glaciers: Moreno, Ameghino and Upsala. Preliminary results are shown to demonstrate the feasibility of the technique.

\subsection{Moreno and Ameghino glaciers}

The velocity pattern on Moreno glacier agrees well with the previously published results based on InSAR. This agrees with the results of the mass balance studies that show that the glacier is in balanced state. The main mass input to the ablation area is supplied trough the southern ice stream. Here the velocity maximum of $3.8 \mathrm{~m} /$ day is shown from TerraSAR-X data. In the lower part of the terminus the velocity decreases with a minimum close to profile $\mathrm{A}$ and increases again close to the calving front.

The velocity at profile $\mathrm{B}$ is shown in Fig. 4. The maximum velocity reaches about $2 \mathrm{~m}$ /day at the center of the glacier. The velocity of Ameghino glacier is smaller, with values below $1 \mathrm{~m} /$ day all over the terminus (Fig. 5). The motion field is similar to the SIR-C observations, when the mean velocity at the calving front was 0.79 $\mathrm{m} /$ day. Ameghino glacier is in retreat, and the calving flux amounts only to a small percentage of the total mass balance.

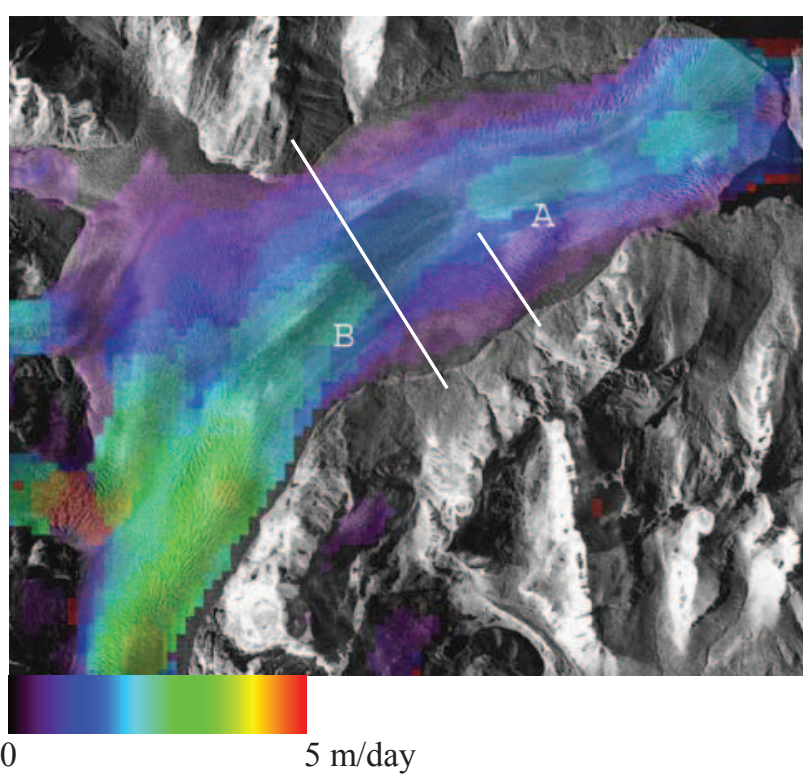

Fig. 3: Map of TerraSAR-X derived magnitude of ice velocity on the terminus of Moreno glacier. At profiles A and $B$ velocities were measured in the field over several years.

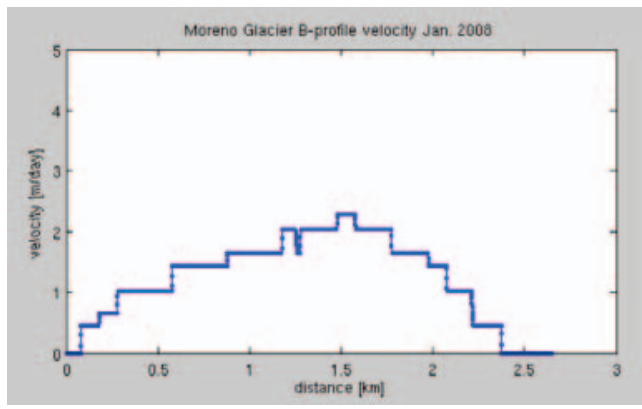

Fig. 4: Ice velocities derived from TerraSAR-X data at the transversal transect B shown in Fig. 3. The Southern margin in on the right side of the plot.

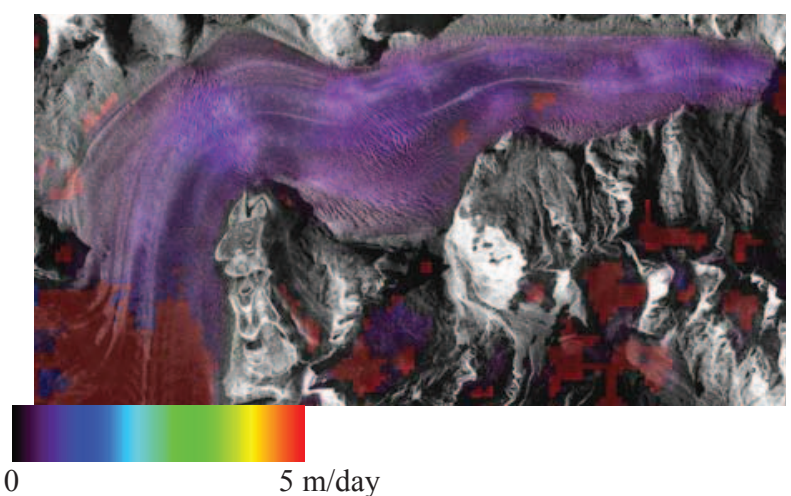

Fig. 5: Map of TerraSAR-X derived magnitude of ice velocity on the terminus of Ameghino glacier. 


\subsection{Upsala glacier}

Previously ice velocities on Upsala glacier were derived only close to the glacier front with traditional surveying methods. Fig. 6 shows the first velocity field of the entire terminus. The frontal velocities reach maximum values of $5.6 \mathrm{~m} /$ day which are larger than the maximum value of $4.9 \mathrm{~m} /$ day. measured in 1993 at stakes in similar location by [4]. The acceleration is very likely caused by effects of reduced friction at the glacier bed. Due to decreasing ice thickness the grounded terminus approaches flotation thickness near the front. This coincides with major frontal retreat during the last several years.

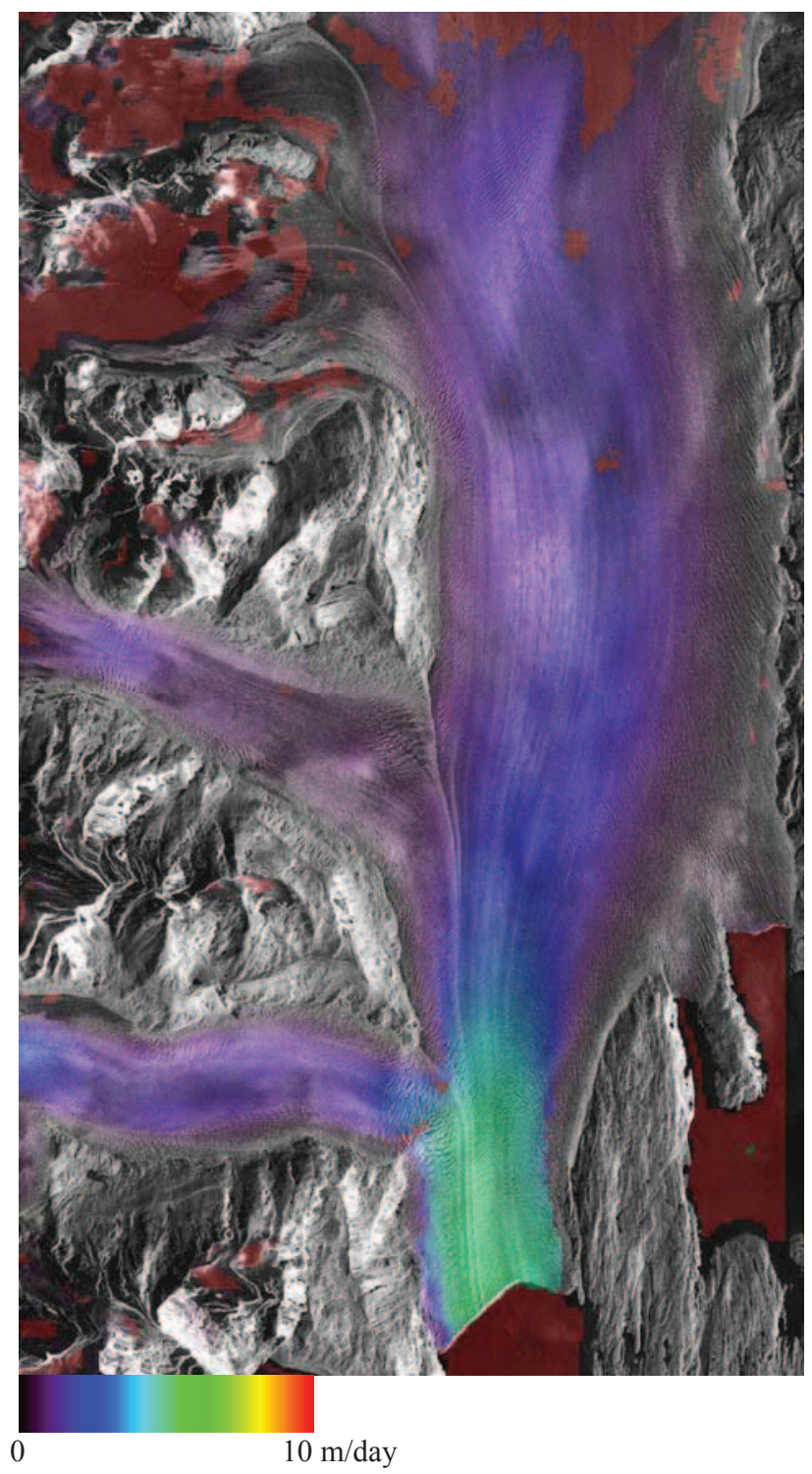

Fig. 6: Map of TerraSAR-X derived magnitude of ice velocity on the terminus of Upsala glacier.

\section{CONCLUSION}

The studies on outlet glaciers of the Patagonia Icefield demonstrate the unique capabilities of TerraSAR-X for mapping and monitoring ice flow and deformation using image correlation techniques. The high spatial resolution and frequent repeat observation capabilities enable detailed observation of complex flow fields and their temporal variations. Advantages of amplitude correlation are the insensitivity to phase decorrelation, the measurement of two components of the velocity vector, and the un-ambiguity of the displacement measurements. The outlet glaciers of the Patagonia Icefield are characterized by high velocities, strong deformation, and rapidly changing meteorological conditions. All these factors cause rapid decorrelation of repeat pass SAR images. Therefore only few and fragmentary InSAR studies have been possible so far on Patagonia glaciers, based on the few available coherent one-day repeat pass InSAR pairs. TerraSAR-X opens up a new stage for observations of glacier dynamics, enabling complete and detailed observations of flow fields also for narrow, fast flowing ice streams and glaciers.

\section{REFERENCES}

[1] Rott H., M. Stuefer, A. Siegel, P. Skvarca P. and A. Eckstaller, "Mass fluxes and dynamics of Moreno Glacier, Southern Patagonia Icefield", Geophys. Res. Lett., Vol. 25(9), 1407-1410, 1998

[2] Stuefer, M., H. Rott, and P. Skvarca, "Glaciar Perito Moreno, Patagonia: climate sensitivities and glacier characteristics preceding the 2003/04 and 2005/06 damming events," Journal of Glaciology, 53 (180), pp. 3-16, 2007.

[3] Casassa, G., A. Rivera, M. Aniya and R. Naruse, Current knowledge of the Southern Patagonia Icefield. In Casassa, G., F.V. Sepúlveda and R. Sinclair, eds. The Patagonian ice fields: a unique natural laboratory for environmental and climate change studies. New York, Kluwer Academic/Plenum Publishers, 67-83,2002.

[4] Skvarca, P., K. Satow, R. Naruse, and J.C. Leiva, "Recent thinning, retreat and flow of Upsala Glacier, Patagonia", Bulletin of Glacier Research, 13 , pp 11-20, 1995.

[5] Stuefer M., "Investigations on mass balance and dynamics of Moreno Glacier based on field measurements and satellite imagery", PhD Thesis, University of Innsbruck, 1999.

[6] TerraSAR-X Ground Segment Basic Product Specification Document Issue 1.5, 2008. 